\title{
Economic Factors in the Use of Renewable Energy Sources in Kazakhstan
}

\author{
Gaukhar Seitkhamzina \\ Department of Economy and Management, Almaty Academy of Economy and Statistics, Almaty 050006, Kazakhstan
}

\begin{abstract}
The purpose of this research was to study economic incentives to use renewable energy sources in the Republic of Kazakhstan and to give suggestions for production and circulation of the "green" certificates as a new financial instrument. The author analyzed European Union and Kazakhstani experience of economic incentives to reduce emissions and introduction of renewable energy sources. As a result of conducted research, the proposal to produce and circulate new financial instruments in Kazakhstan is made; as well as economic and environmental factors of renewable energy sources in the Republic of Kazakhstan are defined.
\end{abstract}

Key words: Renewable energy sources, financial instruments, “green” certificates, “green” economy.

\section{Introduction}

In the beginning of 2009, the Parliament of the Republic of Kazakhstan ratified the Kyoto Protocol, which was signed in 1997 by 125 countries. The purpose of the agreement is to prevent catastrophic climate changes. For the countries who ratified the protocol, quotas for industrial gases emission causing "greenhouse effect" in the atmosphere are allocated. If a state is not capable to hold the necessary level of emissions, it can buy quotas from other states which releases less harmful substances into the atmosphere [1-3].

Decrease in harmful emissions not only will allow people to breathe easier, but also will involve additional investments in economy. Besides, ecologists consider the agreement as an additional incentive for the world countries to search alternative to the present power sources.

Since 2000, national inventory of hotbed gases is conducted in Kazakhstan. In 1992, the general emissions of hotbed gases were 340 million tons, and in 2008 were 247 million tons equivalent to carbon

Corresponding author: Gaukhar Seitkhamzina, Ph.D., professor, research field: economy support of renewable energy sources. E-mail: gau17erj@mail.ru. dioxide [4]. Thus, Kazakhstan has a stock of about 90 million tons of hotbed gases. Kazakhstan is one of the countries with high rate of hydrocarbonic emissions in the world, ranking the eighth place, which speaks about huge potential of its reduction [5].

Today, foreign investors show a great interest in Kazakhstani economy due to high growth of gross domestic product and economic reforms to stimulate attraction of investments into Kazakhstan economy. The Initial Public Offering (IPO) program of the national companies is developed for the attraction of investments. At the same time, the development of additional financial instruments will allow to expand a line of high-rating tools both for external investors and internal investors.

The necessity of this research is defined by the need of forming economic incentives for investment in innovative projects to decrease harmful emissions and introduce renewable energy at the expense of production and circulation of "green” certificates.

\section{Main Economic Factors in the Use of Renewable Energy Sources}

Traditional sources of energy, such as coal, gas and oil, have always been available. Only recently, their 
negative impact on the environment and the high price that society pays for the use of these energy sources (so-called external costs) became obvious. However, in recent years, the growing energy needs of the world economy have incredibly increased the demand for conventional energy sources. As a result, market price of conventional energy rarely reflects their real cost, which society pays for the extraction and use of these fuels. The price of renewable energy sources, which allows to avoid the same damage caused by conventional fuels, is much higher than the cost of fossil fuel resources, due to the high cost of operation [6].

Therefore, on one hand, the function of enabling renewable energy is to maintain the balance in the market, and on the other hand, to compensate for the external costs of renewable energy sources that are incidental to conventional sources of energy [7].

Since late 70 s to early 80 s, many countries began to adopt special renewable energy development programs, for which, over time, substantial amount of funds from state budgets were allocated.

Financial aid was provided variously, but because of its size countries began to recognize the need for effectively tracking systems of different enabling schemes.

One of the requirements was the level of production and consumption of renewable energy in the European Union (EU) member states-not below the established level. Appropriate level has been established both for EU as a whole and for individual countries. EU member states could set bigger tasks and higher levels of energy consumption themselves; but the failure to reach the established and adopted national targets, according to EU rules, results in application of financial penalties against non-complying states [8].

Another important directive requirement was the necessity for EU member states to guarantee the origin of electric energy from renewable energy sources on the basis of criteria established by the directive. This meant that all EU member states must, by specified date, have a system in place that guarantees the origin of electric power from renewable energy sources, as it is the presence of such system that can legitimize the national renewable energy production and consumption records.

Since electric energy is supplied into electric power system in a depersonalized manner, it was necessary to establish the amount of energy coming from renewable sources. First of all, it concerns a high transparency level of information about the electric power sources being sold. At the moment, such transparency requirement is only mandatory in Austria and the Netherlands. In other countries, its fulfillment is a voluntary commitment of energy companies [9].

In practice, power companies inform consumers the share of renewable energy of the total amount of energy supplied by them. This fact must be documented. This is what confirmation certificates are used for. Mandatory condition for the procedure is "repayment" of certificates to confirm the production (supply) and/or consumption of "green” energy. Only repaid certificates are accepted as confirmation. As there are large regional markets in Europe and thus cross-border sale of electric power, in order to avoid "double" sales, it is recommended to put into an international operation system of issuance, registration, circulation and cancellation record of such certificates. This function is performed by renewable energy certificates system (RECS) international association.

It is important to note that the creation of international market of renewable energy certificates is the primary goal of RECS international. The development of export/import of energy from renewable sources automatically raises a question of accompanying the operations with relevant certificates and establishing a registration and tracking system thereof. Renewable energy can be accounted for both its production and consumption. In turn, the energy produced in one country may be consumed in another. Therefore, it is necessary to avoid double counting of 
volume, consumption and sales, which can only be ensured on the basis of strict regulations developed by RECS international.

The use of guarantee certificates is to ensure the development of voluntary commitments by corporations. Renewable energy certificates can be used not only by the state but also by individual companies to confirm the performance of their environmental or social obligations. While in the first case, these are mainly statistical tools in case of the use of certificates by companies to confirm their voluntarily undertaken obligations; they may become a subject of commercial turnover. The government may create additional incentives for companies to undertake and fulfill voluntary commitments in relation to production, supply or use of energy from renewable sources.

Production obligations may lay, of course, on energy producers, and consumption obligations may lay on consumers and producers. In turn, among all of the potential consumer groups, some may stand out for different reasons: state and commercial budget financing organizations, production and services companies/organizations, legal entities and individual consumers, etc..

Furthermore, according to the policy adopted by a government in regard to production and consumption of renewable energy, there are several different combinations of such groups and requirements for them. For example, in some countries, the obligations are only imposed on suppliers; in some countries the obligations are imposed on producers and importers; and in other countries, the obligations are imposed on consumers. Sometimes, the renewable energy utilization rates are established for different groups of consumers at different levels. For example, more environmentally "polluted" consumers get a higher rate of consumption.

In order to confirm performance of the imposed obligations to the government, manufacturers can start producing energy from renewable energy sources themselves, or use energy produced by other companies. Consumers, in turn, may also become producers of renewable energy, or similarly, use energy produced by respective companies. Government establishes terms, conditions and procedures for the obligatory confirmation of production, supply and consumption of energy from renewable energy sources. In the same way, the government defines the procedure for issuing certificates and conditions of usage at all stages of their issuance and circulation [10].

It is important to note that both mandatory and voluntary systems for confirmation of the use of renewable energy sources (RES) are allowed. For example, the above scheme of imposing obligations on companies for production and (or) use of energy from renewable sources, of course, should be regarded as a mandatory system. In this case, companies have no choice - the obligations imposed by state are not subject for discussion. The only alternative to non-fulfillment of obligations is payment of fines. Usually, the amount of fines is $10 \%-20 \%$ higher than marginal price of certificates in the market.

Such system of fines is, in addition, a form of protection of buyers from voluntarism of sellers or from sharp increase in the price of certificates on free market. The buyer may refuse to purchase and repayment of renewable energy certificates and may prefer to pay a fine, which will still be lower than current price of certificates.

The system for undertaking of such commitments is voluntary. And it is linked to the concept of sustainable development and corporate social responsibility. Companies who undertake voluntary obligations will be characterized as responsible agents on the territory where they conduct their business. These obligations may include the cooperation with local authorities and public organizations, special constructive cooperation relationship with trade unions and maintaining a high level of environmental protection. 
The above obligations should have a formal publication of performance confirmation, which is reflected in special annual reports, similar to annual corporate reports prepared and issued by public companies, primarily for shareholders and investors. Just as annual reports of corporations are not accepted by auditors without official confirmation of information contained in the balance sheet, the reports under corporate social responsibilities should have a similar assurance. Therefore, the evaluation of their performance is just as strict as verification of the financial obligations of corporations to their shareholders and investors. Also, just like regular annual reports, corporate reports on the performance of obligations under social responsibilities are subject to thorough investigation. Investors believe that companies that are "good" corporate citizens on their businesses territory, if they have a higher sustainability than those do not give enough attention and resources to these issues. Thus, social obligations are converted into a rising cost of capitalization of the companies that undertake them [1].

Part of these social obligations is about energy consumption from renewable energy sources to different extents. This may be used in production process, or used for offices lighting, if the company is not industrial. In order to confirm the performance of these specific obligations to the stated extent, companies must submit to auditors the canceled renewable energy certificates, which they can buy from producers of this energy. This is how certificates market begins to develop with certificates, which confirm execution of voluntary obligations, and this is how their price is formed.

Many companies and corporations undertake voluntary obligations to use renewable energy for their own production or commercial purposes. There are two basic ways to perform them. The first one is to build facilities to generate renewable energy: installation of solar panels on the roofs of their buildings and their facades, wind turbines "in the backyard" and various combined systems. The second way is to confirm the use of renewable energy produced by someone else. An appropriate confirmation and construction of own renewable generation plant should cost money. In the first case, it is a question of the cost of investments and operation of power plants; in the second case, it is a matter of the purchase of confirmation certificates. In turn, the certificates need not to be strictly national; certificates can be bought from other countries, if it permitted by the rules of obligations confirmation and if these certificates are harmonized according to the rules of RECS International. It is important for the certificates to be reliably verified and properly accounted for the production and consumption of renewable energy in its origin and exported country.

\section{Use Certificates in Renewable Energy Sources Enabling Schemes}

Certificates are not a form of enabling renewable energy sources. At the same time, guarantee or "green" certificates are often part of various renewable energy sources enabling schemes or they "stand" next to those. This approach may have a variety of implementation forms. In some cases, the government establishes mandatory quotas of renewable energy used by different consumers. Their set is determined on the basis of political, social and economic priorities. For example, it may be all industrial consumers of electric power, only chemists or metallurgists, enterprises with the highest levels of environmental pollution, or enterprises subject to certain quantitative limits: sales, number of employees, location, etc.. In this case, the confirmation of the use of renewable energy will be precisely based on such already cancelled guarantee or "green" certificates [2].

Another scheme may involve the provisions of subsidies, markups or other financial assistance to energy generators based on renewable energy. Its extent is usually tied to the volume of energy produced or sold. This in turn must be confirmed 
through guarantee or "green” certificates.

It is important to understand that although the certificates themselves are not an instrument of support, without them it is difficult to build a harmonious system, which ensures equitable redistribution of resources to compensate for higher costs of RES generators. At the same time, certificates can be documents - the basis for such support, the subject to purchase/sale, or a source of revenue for renewable energy generators [11].

\section{Conclusions}

“Green” certifications are essentially carriers of certain rights to renewable energy.

Industrialized countries have already formed a certain system methods for economic incentives for environmental activities, which greatly supplement administrative control.

For Kazakhstan, it is essential to apply the best international practices for the production and circulation of green certificates and to implement effective mechanism to stimulate investment activity in the field of renewable energy sources through introduction of new financial instruments.

Having analyzed international practices and possible government stimulation methods of alternative energy development, one can come to the conclusion that it is impossible to do without introduction of "green certificates" system; and government incentives should be implemented as flexibly as possible in stages and focus on small and medium businesses.

While the expansion of international cooperation, in order to transit to a "green" economy from energy-intensive industrial production, aimed at modernizing real economy sector, strengthening of national capacities and increasing the country's access to advanced technology which complies with the national interest of the Republic of Kazakhstan on sustainable development; it is necessary to emphasize the importance of international assistance in development of "green" economy by strengthening the role of developed countries and international organizations in creating favorable conditions for access to "green” technologies and ensuring effective international cooperation in the field of sustainable development.

\section{References}

[1] Koshumbaev, M. B. 2011. "Kyoto Protocol and Legislative Initiative." J. Power Economy and Fuel Resources of Kazakhstan 6: 79-82. (in Russian)

[2] Koshumbaev, M. B. 2011. "Kyoto Protocol and Recommendations for Economic Incentives.” $J$. Newsletter of Kokshetau Engineering 3: 3-6. (in Russian)

[3] Adilov, T. A. 2009. "Realization of Mechanisms of the Kyoto Protocol.” Coordination Council on Development of Oil and Gas Branch of "KazEnergy" Association, Astana. Accessed December 30, 2009. http://www.kazenergy.com/2012-09-05-04-11-04/325-30 102009-adilov-ta.html. (in Russian)

[4] JSC Gazprom. 2005. "Inventory of Emissions of Hotbed Gases.” Accessed October 25, 2005. http://www.complexdoc.ru/ntdtext/537242/2. (in Russian).

[5] Ministry of the Environment Republic of Kazakhstan and United Nations Development Programme (UNDP). 2010. Capacity Building in a Sustainable Development through Integration of Questions of Climate Change into Strategic Planning in the Republic of Kazakhstan. (in Russian)

[6] Girusova, E. V., and Lopatin, V. N. 2003. Ecology and Environmental Management Economy. Moscow: Yuniti-Dana Publisher, 519. (in Russian)

[7] Kopylov, A. E., and Zerchaninova, I. L. 2006. Renewable Energy "Green" Certificates Mechanisms and Usability Thereof in Russia. Moscow: Eco Publisher, 56-7. (in Russian)

[8] Lysenko, R., and Fazylov, D. 2010. "Wind Power Development Problems in Kazakhstan.” J. Power Economy 35: 56-62. (in Russian)

[9] Seitkhamzina, G., and Ashimova, A. 2013. "Encouraging the Introduction of Renewable Energy Sources through the Introduction of New Financial Instruments- 'Green' Certificates." In Proceedings of the 4th Eurasian Economic Youth Forum-Dialogue of Civilizations: Youth Global Mind, 15-6. (in Russian)

[10] Koshumbaev, M., and Seitkhamzina, G. 2013. "Mechanism for Introducing New Financial Instruments- 'Green' Certificates, in the Light of the Kyoto Protocol.” J. Intellectual Property in Kazakhstan 1: 46-53. (in Russian)

[11] Seitkhamzina, G., and Bekenova, L. 2014. "Priorities of 
Applying New Financial Instruments in the Field of Introducing RES in Kazakhstan.” In Proceedings of the
International Conference on Science and Education in XXI Century, 170-1. (in Russian) 